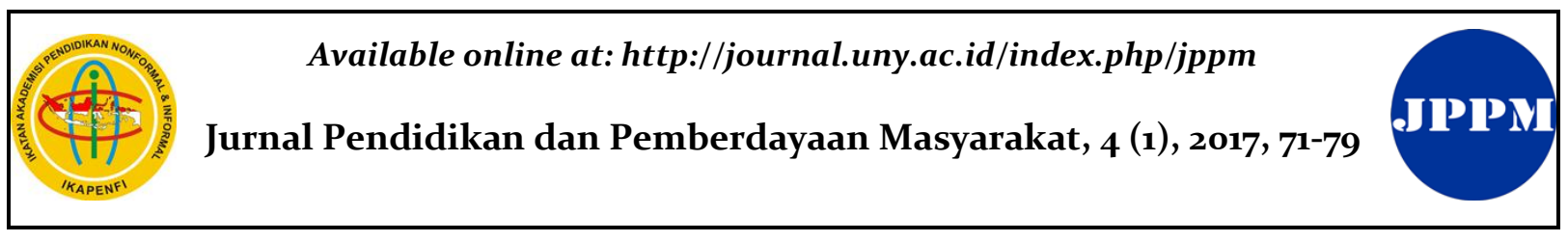

\title{
Keterlibatan Orangtua dalam Needs Asesment Pengembangan Komunikasi Anak Cerebral Palsy
}

\author{
M. Mumpuniarti ${ }^{1}$,, S. Sukinah ${ }^{2}$, P. Pujaningsih ${ }^{3}$ \\ ${ }^{123}$ Pendidikan Luar Biasa, Fakultas Ilmu Pendidikan, Universitas Negeri Yogyakarta. Jalan \\ Colombo No 1, Karangmalang, Yogyakarta 55281, Indonesia \\ * Korespondensi Penulis. Email: mumpuni@uny.ac.id \\ Received: 28 October 2016; Revised: 1 March 2017; Accepted: 22 March 2017
}

\begin{abstract}
Abstrak
Penelitian bertujuan menggali tindakan dan harapan yang dapat dilakukan oleh orang tua yang memiliki anak Cerebral Palsy, khususnya dalam mengembangkan kemampuan berkomunikasi. Hambatan komunikasi dan kognitif yang mayoritas dimiliki oleh anak Cerebral Palsy (CP) tetap harus dioptimalkan dengan menggunakan komunikasi alternatif dan tambahan (Augmentative and Alternative Communication/AAC). Untuk itu, perlu dikembangkan media komunikasi tersebut dan kemampuan menggunakan oleh anak Cerebral Palsy diperlukan keterlibatan orang tua. Oleh karena itu, penelitian dilakukan dengan tindakan partisipasi antara peneliti dan orang tua melalui mendampingi orang tua agar supaya orang tua mampu membuat media, serta mengimplementasikan bagi anaknya yang Cerebral Palsy. Partisipasi orang tua digali dengan angket, wawancara, dan observasi. Hasil penelitian menunjukkan bahwa 95\% dari orang tua membutuhkan anaknya dapat dengan AAC, demikian juga kebutuhan (need) asesmen masih pada kebutuhan level awal komunikasi. Kondisi itu berimplikasi mengembangkan komunikasi yang dibutuhkan untuk kehidupan sehari-hari di lingkungan keluarga. AAC yang dipilih lebih ke arah miniatur benda asli dan kartu gambar.
\end{abstract}

Kata Kunci: Komunikasi AAC Cerebral Palsy (CP)

\section{Parental Involvement in the Needs Assessment of Cerebral Palsy Children Communication Development}

\begin{abstract}
The study aims to explore the actions and expectations can be done by parents of children with Cerebral Palsy, particularly in developing communication skills. Barriers to communication and cognitive majority owned by the child's Cerebral Palsy $(C P)$ remains to be optimized by using alternative and additional communication (augmentative and Alternative Communication/ $A A C)$. For it is necessary to develop the communications media and the ability to use the Cerebral Palsy children need parental involvement. Therefore, the research carried out with the participation of action between researchers and parents through assisting the parents so that parents can make the media, as well as implements for Cerebral Palsy children. Participation of parents dug with questionnaires, interviews, and observations. The results showed that $95 \%$ of parents in need of child can be with $A A C$, so does the need (need) assessment is still at the initial level of communication needs. The condition is implicated develop communication needed for daily life in the family environment. AAC selected more towards miniaturized original objects and picture cards.
\end{abstract}

Keywords: Communication with AAC of Cerebral Palsy

How to Cite: Mumpuniarti, M., Sukinah, S., \& Pujaningsih, P. (2017). Keterlibatan orangtua dalam needs asesment pengembangan komunikasi anak cerebral palsy. Jurnal Pendidikan dan Pemberdayaan Masyarakat, 4(1), 71-79. doi:http://dx.doi.org/10.21831/jppm.v4i1.11464 


\section{Jurnal Pendidikan dan Pemberdayaan Masyarakat, 4 (1), March 2017 - 72}

M. Mumpuniarti, S. Sukinah, P. Pujaningsih

\section{PENDAHULUAN}

Peranan orang tua dalam pendidikan anaknya amat krusial, karena beliau sebagai orang pokok terbentuknya keluarga. Haryanto (2011, pp. 19-20) mengemukakan konsep tri pusat pendidikan yang diambil dari konsep pendidikan Ki Hadjar Dewantara yang terdiri keluarga, sekolah, masyarakat, namun berpendapat bahwa keluarga masih merupakan pusat pendidikan yang utama dan terpenting. Pembentuk pokok keluarga adalah orang tua, sehingga tanggung jawab pusat pendidikan yang utama dan terpenting pada orang tua. Sumarno (2011, pp. 8o-81) mengemukakan bahwa keluarga merupakan pendidikan informal yang berfungsi sebagai penyedia atau pengguna, tetapi tidak perjanjian kedua belah pihak. Maksudnya pendidikan dalam keluarga, pada orang tua mendidik anakanaknya dengan sengaja berdasarkan citacita dan harapan kepada anak-anaknya, tetapi si anak tidak memilih lahir dan akan dididik oleh orang tua dengan karakter atau kondisi tertentu. Implikasi pendapat tersebut bahwa pendidikan dalam keluarga yang dilakukan oleh orang tua merupakan konskuensi untuk membentuk keluarga dengan cita-cita yang luhur. Orang tua semuanya pasti bercita-cita dan harapan kepada keberadaan anak-anaknya sebagai generasi penerus yang mampu dewasa dan hidup dalam masyarakat.

Demikian juga, bagi orang tua yang mendapatkan anak Cerebral Palsy tidak dapat dielakkan tetap bertanggung jawab untuk sebagai pendidik utama dan amat krusial dari perkembangan anaknya yang CP. Walaupun, kehadiran anak CP bukan sesuatu yang diharapkan. Orang tua ketika mendapatkan anaknya yang Cerebral Palsy pasti banyak yang terjadi mengalami hilang atau putus harapan (hopeless). Hal itu juga dikemukakan oleh Hardman, Drew, \& Egan (2002, p. 459) bahwa reaksi yang ditunjukkan orang tua ketika mengetahui bahwa anaknya sebagai anak yang disabilitas muncul sikap sedih, berkabung, melemparkan kesalahan pada pihak lain, lebih-lebih ketika seorang bayi lahir sudah terlihat akan terjadi emosional yang amat shock. Pengembalian kepada kondisi untuk menerima keadaan anaknya dan secara bertahap memiliki harapan untuk dapat mengoptimalkan anaknya dari kondisi dianggap tidak dapat berkembang adalah sebuah perjuangan yang harus dilakukan secara bertahap. Untuk itu, kondisi tersebut merupakan sebuah tantangan ketika mereka dimotivasi untuk berperan sebagai pendidik yang utama. Hal itu juga merujuk dari Sumarno (2011, p. 81) bahwa pendidikan dalam keluarga oleh orang tua sebagai pendidikan informal yang memiliki fleksibilitas, daya jangkauan yang lebih luas, dan terjadinya kontinuitas.

Gangguan bicara terdapat 70 persen pada anak-anak $\mathrm{CP}$, dan 88 persen disabilitas bicara didapatkan pada penyandang Cerebral Palsy tipe athetoid, 80\%; pada tipe ataxia $85 \%$; serta $52 \%$ pada tipe spastik (Reynolds \& Fletcher-Janzen, 2008, p. 389). Persentase itu sebagai indikator bahwa pada tipe yang lebih berat, yaitu tipe athetoid ada yang mengalami problem bicara. Tipe athetoid merupakan tipe $\mathrm{CP}$ dengan hambatan neuromuscular yang tidak mampu dikendalikan, sehingga pada otot yang digunakan bicara juga sulit dikoordinasi untuk menghasilkan suara untuk bicara. Pada tipe spastik ditunjukkan amat pelan, amat sulit, vokalnya kurang jelas, kualitas suara kurang bernafas atau serak, volume tidak terkontrol, dan problem artikulasi kabur, dan gerakan yang tidak sinkron antara gerakan lidah, bibir, dan rahang. Bagi tipe athetoid terjadi problem bicara dengan pola gerakan alat bicara yang tidak dapat diatur, dangkal volume suara, dan gangguan artikulasi yang seperti hanya berdesis atau fonem yang serak/parau. Hal tersebut dikarenakan problem pada koordinasi otot-otot yang digunakan produksi bicara, sehingga kualitas bicara menggunakan verbal amat sulit dicapai. Kesulitan dalam memproduksi suara untuk bicara berakibat terhadap kompetensi komunikasi. Komunikasi dengan saluran suara dari bahasa verbal akan terhambat, karena kualitas suara yang digunakan untuk menyampaikan pesan sulit dimakna (decoding) atau diproses kodenya kembali (encoding) secara timbal balik.

Proses penyampaian pesan melalui decoding dan encoding merupakan substansi 
dalam komunikasi, proses tersebut terdapat pada sumber (Kauffman \& Hallahan, 2011, p. 221). Selanjutnya, dikemukakan juga bahwa untuk menegakkan keberhasilan komunikasi bergantung pada kombinasi faktor kontekstual dan faktor individual. Faktor individual pada individu CP menentukan kesulitan dalam berkomunikasi, karena selain kesulitan dalam menggunakan kualitas suara juga pada umumnya Cerebral Palsy mengalami hambatan kognitif. Hambatan kognitif berpengaruh pada penguasaan dari code yang berfungsi informasi transmition. Demikian juga, faktor hambatan kognitif ini perlu didukung oleh faktor kontekstual yang diciptakan oleh keluarga, khususnya orang tua, sehingga keterlibatan orang tua amat krusial. Kode-kode yang diciptakan oleh orang tua diasumsi lebih kontekstual dengan kehidupan sehari-hari anak, sehingga menjembatani hambatan kognitif anak Cerebral Palsy dengan kode yang kontekstualnya konkrit atau tidak abstrak. Kode tersebut untuk mendukung komunikasi fungsional. Demikian dikemukakan Light (1989, p. 138) "Functionality of communication implies utility withinthe demands of daily living. Functional skills are skills that are required within the natural environment: these skills must be performed by others when individuals are unable to fulfill the skill requirements themselves." Untuk itu, komunikasi fungsional bagi CP agar supaya fungsional dibutuhkan keterlibatan dari lingkungan yang natural, yaitu lingkungan keluarga.

Keterlibatan orang tua menentukan keberhasilan perkembangan komunikasi anak Cerebral Palsy, karena konteks kehidupan sehari-hari lebih dihayati oleh orang tua. Demikian juga, tanggung jawab orang tua menentukan keberhasilan pendidikan. Hal itu juga disampaikan oleh Yuliyati (2014, p. 18) bahwa guru memiliki tanggung jawab untuk mengembangkan komunikasi peserta didik melalui mata pelajaran bahasa Indonesia, namun keberhasilan juga merupakan tanggung jawab semua pihak, yaitu guru, pemerintah, masyarakat, dan orang tua. Keberhasilan komunikasi bagi Cerebral Palsy amat krusial terletak pada orang tua, khususnya dalam mengembangkan komunikasi tambahan dan alternatif (Augmentative and
Alternative Communication/AAC). AAC merupakan alternatif dari bentuk komunikasi yang tidak.menggunakan suara seperti halnya bicara atau sebagai pelengkap dari bicara (Hallahan \& Kauffman, 2003, p. 402). Kode atau koding dalam komunikasi dengan sistem AAC dapat digunakan gambar, benda asli yang dibuat sketsa, atau berupa photo yang mewakili sesuatu tentang pesan. AAC bagi Cerebral Palsy amat membantu dalam komunikasi, karena hambatan kognitif juga terbantu oleh penggunaan kode-kode yang konkrit dalam bentuk gambar atau simbol miniature dari benda, kegiatan, dan peristiwa. Demikian juga, AAC membantu Cerebral Palsy menyampaikan pesan komunikasi tanpa harus bersusah payah dengan berbicara.

Penggunaan AAC sebagai komunikasi Cerebral Palsy perlu digunakan secara pembiasaan dalam lingkungan kehidupan anak. Pembiasaan itu merujuk pada teori behavioristik yang dikembangkan Skinner (1957 dalam Dunlap, 2009, p. 123) bahwa perkembangan bahasa diperlukan suatu latihan pembiasaan dengan penggunaan operant conditioning. Pembiasaan ini amat krusial adanya keterlibatan orang tua dalam melatih. Keterlibatan yang dibutuhkan di antaranya dalam identifikasi dan asesmen kosa kata yang amat diperlukan anak Cerebral Palsy dalam keluarga. Kebutuhan itu kosa kata yang dikembangkan dengan AAC supaya fungsional. Komunikasi dengan sistem AAC harus dikembangkan ke arah untuk membantu anak perolehan komunikasi fungsioanal (Dunlap, 2009, p. 148). Hal itu juga dikuatkan oleh sumber Hallahan \& Kauffman (2003, p. 283) bahwa pengembangan komunikasi harus dikaitkan dengan benda dan aktivitas dalam budaya anak dan keluarga. Kosa kata fungsional mendukung juga intensitas penggunaan komunikasi. Hal ini juga terbukti oleh review penelitian dilakukan oleh Millar, Light, \& Schlosser (2016, pp. 251-253) bahwa AAC memberi keuntungan perkembangan komunikasi, terutama bagi anak-anak yang hambatan perkembangan/developmental disabilities. Dengan demikian, AAC dengan penggunaan kode yang terkait kehidupan sehari-hari fungsional bagi anak-anak yang mengalami ham- 
batan koginitif dan juga bagi anak yang tidak mampu komunikasi dengan suara verbal.

\section{METODE}

Metode yang digunakan dalam kegiatan program pengabdian adalah angket dengan cara para orangtua mengisi istrumen tersebut tentang kebutuhan pengembangan komunikasi bagi anak masing-masing. Beberapa metode yang diterapkan adalah penilaian kinerja saat pendampingan untuk mengetahui kemampuan awal, kemampuan akhir, demonstrasi dan simulasi untuk materi yang bersifat praktik aplikatif, dan penugasan terstruktur yang didampingi sehingga peserta menghasilkan karya yang fungsional bagi masing-masing anak. Pengembangan komunikasi dengan sistem AAC bagi Cerebral Palsy melalui keterlibatan orang tua, dilaksanakan dengan langkah-langkah seperti dalam Gambar 1.

Langkah tersebut dijelaskan secara berturut-turut: (1) Bersama orang tua dari anak Cerebral Palsy membahas tentang ide perlunya membantu untuk solusi problem bicara putra/putrinya; (2) Persetujuan antara kedua belah pihak dari tim pengabdi dan orang tua kita laksanakan sosialisssi tentang potensi komunikasi anak Cerebral Palsy dari beberapa kasus; (3) Ceramah tentang konsep media dan fungsi penggunaan media; (4) Pelatihan pembuatan media AAC; (5) Praktek pembuatan AAC bersama tim dan orang tua; (6) Hasil dari sosialisasi, ceramah, dan praktek AAC memberikan wasasan kepada orang tua tentang kebutuhan komunikasi putra/putrinya sehingga kebutuhan itu sebagai dasar dilakukan asesmen oleh tim; (7) Selanjutnya, diskusi kasus (case conference) untuk keputusan langkah pembuatan media AAC dan hasil pembuatan media oleh orang tua untuk dipraktekkan bersama dengan putra/putrinya; (8) Hasil dari praktek yang dilakukan oleh orang tua terhadap anaknya yang Cerebral Palsy sebagai refleksi dan evaluasi tentang peningkatan kemamapuan komunikasi anak Cerebral Palsy dengan AAC melalui peran yang dilakukan oleh orang tua.

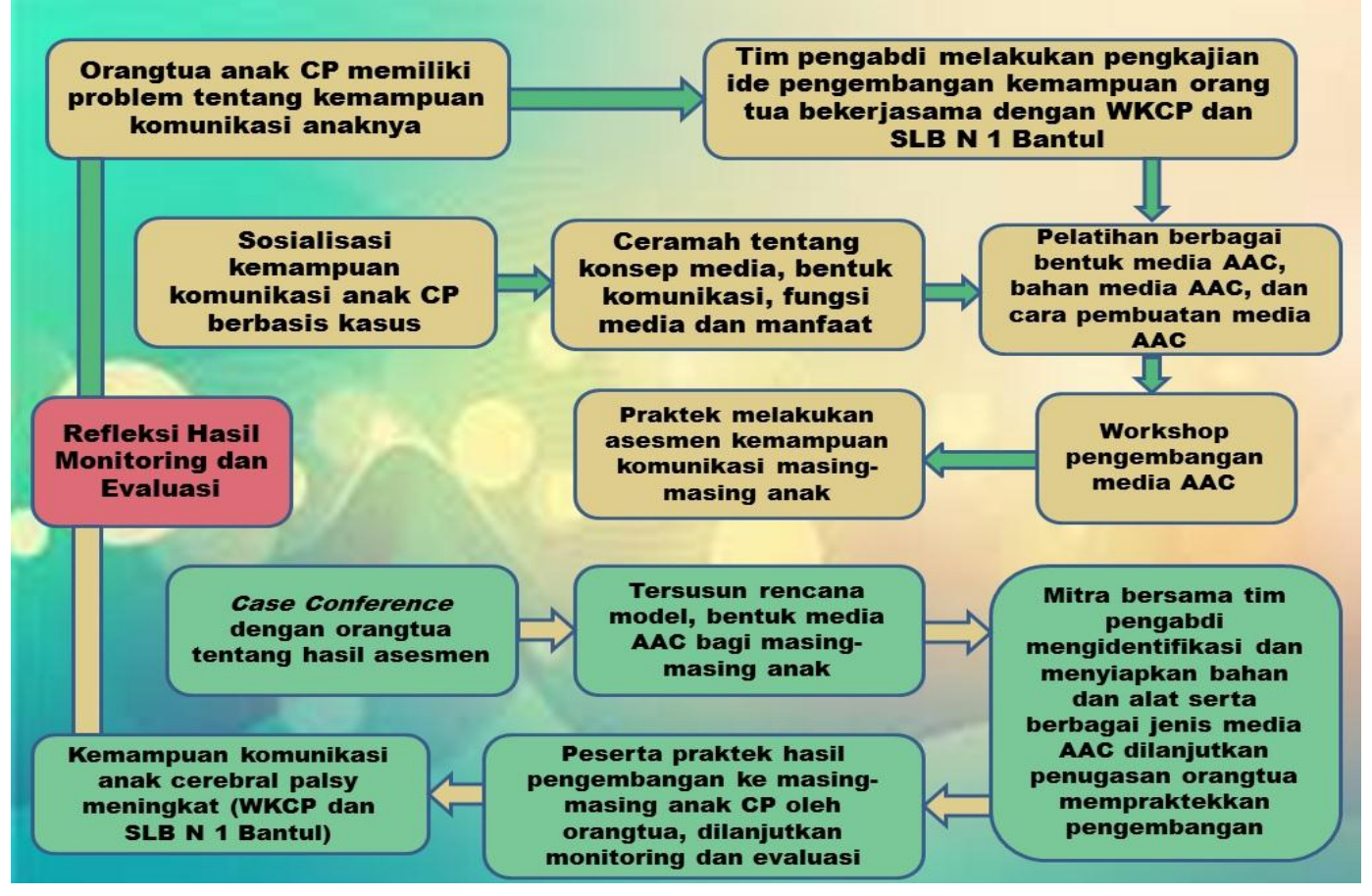

Gambar 1. Langkah-langkah Pengembangan komunikasi dengan sistem AAC bagi Cerebral Palsy melalui keterlibatan orang tua 


\section{Jurnal Pendidikan dan Pemberdayaan Masyarakat, 4 (1), March 2017 - 75}

M. Mumpuniarti, S. Sukinah, P. Pujaningsih

\section{HASIL DAN PEMBAHASAN}

\section{Hasil}

Dalam pelaksanaan pengabdian kepada masyarakat diperlukan keterlibatan orangtua untuk melaksanakan needs asesment sebagai upaya pengembangan komunikasi bagi anak Cerebral Palsy. Keterlibatan orangtua dalam melakukan asesment awal sebanyak 35 orangtua yang memiliki anak Cerebral Palsy. Hasil asesment menunjukkan bahwa dari orangtua secara persentase 95\% merasa kesulitan untuk berkomunikasi dengan anak saya, $85 \%$ permasalahan komunikasi belum terpecahkan, 90\% kesulitan dalam memahami keinginan anak, $20 \%$ menggunakan media komunikasi untuk mempermudah putra/putri mengungkapkan keinginannya, $10 \%$ orangtua sudah banyak mengenal media alternatif komunikasi untuk putra/putri, $85 \%$ Merasa memerlukan pengetahuan tentang pengembangan komunikasi untuk putra/putri, 70\% Sanggup mengikuti serangkaian kegiatan yang akan diberikan dalam proses sosialisasi sampai pendampingan pengembangan media komunikasi. Demikian juga aspek lainnya orangtua menyatakan 90\% membutuhkan keterampilan dalam pengembangan media alternatif komunikasi untuk putra/putrinya, 70\% orangtua ingin mewujudkan dalam bentuk media komunikasi yang lebih fungsional untuk anak saya dalam kehidupan seharihari, $90 \%$ orangtua akan meluangkan waktu untuk lebih fokus mengembangkan media alternatif komunikasi untuk anak saya, 95\% orangtua memiliki harapan agar supaya anak mampu mengungkapkan keinginanny, 80\% orangtua mengharap anaknya memunculkan perilaku-perilaku tertentu jika tidak terpenuhi keinginannnya. Sedangkan aspek lainya 90\% orangtua masih berpendapat bahwa anaknya untuk berkomunikasi harus menggunakan bahasa verbal, 6o\% anaknya dalam berkomunikasi menggunakan bahasa isyarat, 80\% orangtua masih kesulitan mencari komunikasi alternatif bagi anaknya, 50\% orangtua menyatakan anaknya dapat berkomunikasi menggunakan isyarat, $70 \%$ orangtua selalu berusaha keras menemukan dan mengembangkan komunikasi alternatif bagi putranya dan $100 \%$ Mempunyai harapan manfaat melalui keikutsertaan pelatihan.

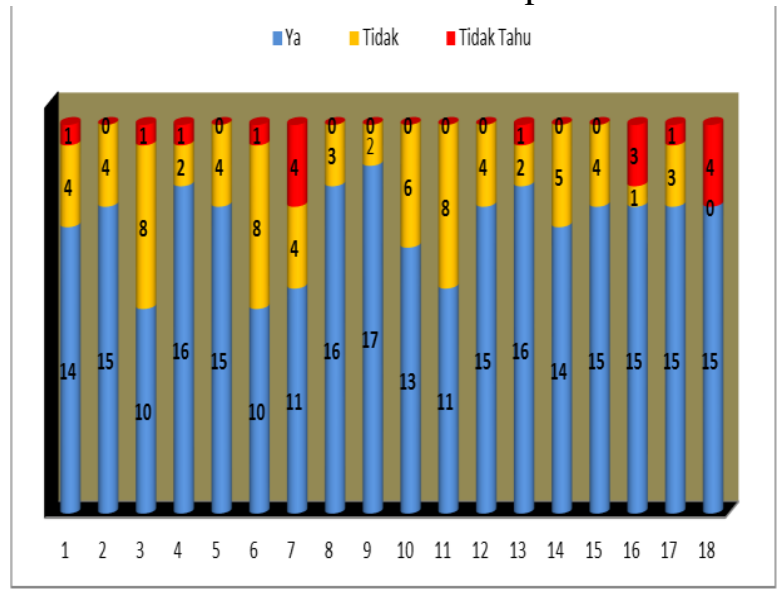

Gambar 2. Grafik Rekap Data Need Assesment Pengembangan AAC Anak CP bagi Orang Tua

Penjelasan grafik yang pada nomor 1 tersebut menunjukkan bahwa orang tua mayoritas menyatakan "ya" membutuhkan latihan komunikasi bagi putranya dan berharap putranya mampu berkomunikasi. Hal itu ditandai pada grafik dengan tanda/warna biru dari 18 (delapan belas) item yang diajukan tentang kebutuhan (need asesmen) pengembangan AAC.

Hasil asesment menunjukkan kemampuan komunikasi subjek yang memiliki level 1 ada 10 anak Cerebral Palsy. Adapun aspek kemampuan yang dimiliki anak dalam level 1 meliputi aspek-aspek berikut; Tidak menoleh jika dipanggil, seperti tidak mendengar, Jika diajak bicara tidak ada kontak mata, Sama sekali tidak berminat untuk bermain dengan teman sebayanya, Tidak bisa mengekspresikan perasaan gembira, sedih, dan marah, Terikat pada objek tertentu atau kegiatan tertentu, Sama sekali belum bisa berbicara, Sangat sering melakukan stimulasi diri, Tidak bisa menahan/menunda keinginan sesaat dan eolah-olah tidak melihat dan tidak mendengarkan apa yang terjadi. Adapun rangkuman tabel asesmen AAC level 1, dapat dilihat pada Gambar 3. 
Jurnal Pendidikan dan Pemberdayaan Masyarakat, 4 (1), March 2017 - 76

M. Mumpuniarti, S. Sukinah, P. Pujaningsih

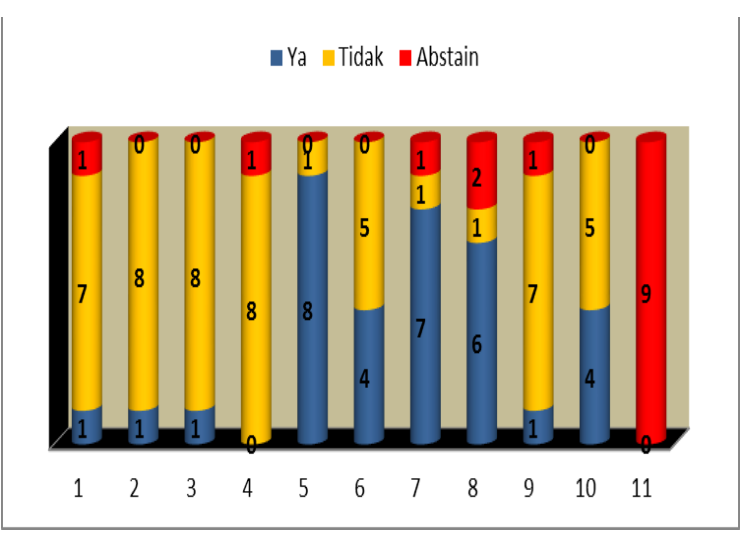

Gambar 3. Grafik Rekap Data Instrumen Assesmen AAC Level 1

Gambar 3 adalah hasil asesmen tentang kondisi komunikasi dari subjek yang menyatakan bahwa indikator 5, 6, 7, 8 sebagai indikator keinginan berkomunikasi, tetapi terbatas di dalam menyampaikan. Hal ini terlihat jelas bahwa mereka membutuhkan komunikasi dengan sistem AAC. Hasil asesmen selanjutnya di level 2 juga hampir amat perlu untuk latihan komunikasi AAC., karena mereka sudah Nampak berekspresi untuk komunikasi tetapi terbatas untuk mediasi untuk menyampaikan.

Hasil asesmen orangtua terhadap kemampuan anak berkomunikasi untuk level 2 ada 11 anak dengan menunjukkan kemampuan anak Jika meninginkan sesuatu menarik tangan orang lain untuk mengambilnya, Jika dipanggil namanya dapat menoleh, Sudah ada inisiatif untuk berinteraksi dengan orang lain, Sudah mulai ada pengertian terhadap perintah, Sudah mulai dapat meniru kata-kata yang diucapkan orang lain, Mulai dapat memperhatikan objek yang ditunjukkan, Mulai dapat mengekspresikan perasaan, senang dan sedih, Mulai dapat menunjukkan ekspresi marah, Ada minat untuk berinteraksi dengan orang lain, Ada kontak mata ketika diajak bicara

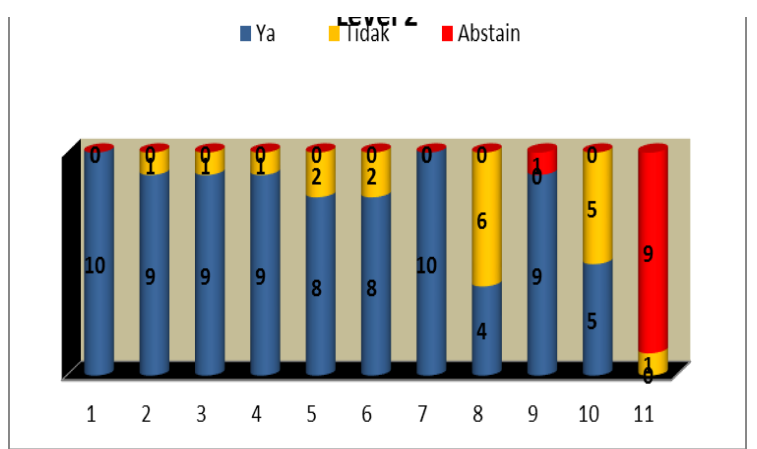

Gambar 4. Grafik Rekap Data Instrumen Assesmen AAC Level 2

Hal tersebut telah terlihat bahwa pada level 2 indikator 1, 2, sampai 9 menunjukkan mereka membutuhkan komunikasi AAC, karena aktualisasi berkomunikasi dan interaksi sudah ditunjukkan dengan keterbatasan cara menyampaikan dengan suara.

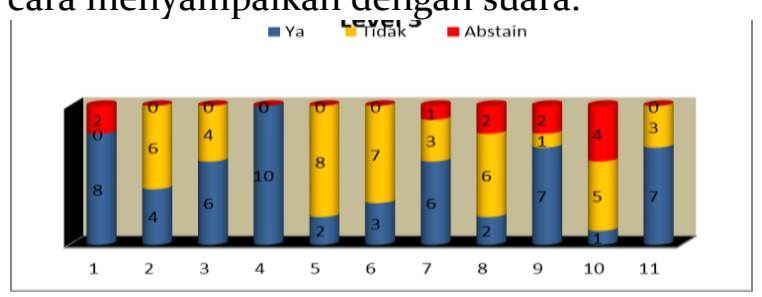

Gambar 5. Grafik Rekap Data Instrumen Assesmen AAC Level 3

Pada level 3 ada 11 anak yang memiliki perkembangan komunikasi yang berfungsi untuk berhubungan dan berinteraksi dengan orang lain semakin amat diperlukan, karena masih terlihat secara grafik berada di posisi warna biru yang rendah. Untuk itu, latihan AAC juga perlu dikembangkan juga pada kemampuan untuk berinteraksi timbal balik dan berperan serta secara sosial dengan pihak lain. Sedangkan anak yang memiliki komunikasi level 4 berdasarkan indicator berikut: Mulai dapat mendengarkan ketika orang lain berbicara kepadanya, Dapat mengungkapkan sesuatu dengan kalimat pendek lengkap, Sudah dapat berbicara timbal balik dengan durasi yang panjang, Mulai dapat mengajukan pertanyaan, Mulai dapat memberikan jawaban sesuai dengan pertanyaan, Dapat melakukan interaksi komunikasi bertujuan, Tumbuh inisiatif untuk bermain dengan teman sebaya, Ada inisiatif untuk mengawali interaksi komunikasi, Dapat bermain secara simbolik dengan teman sebaya dan Sudah mulai dapat menyapa orang lain dengan benar 


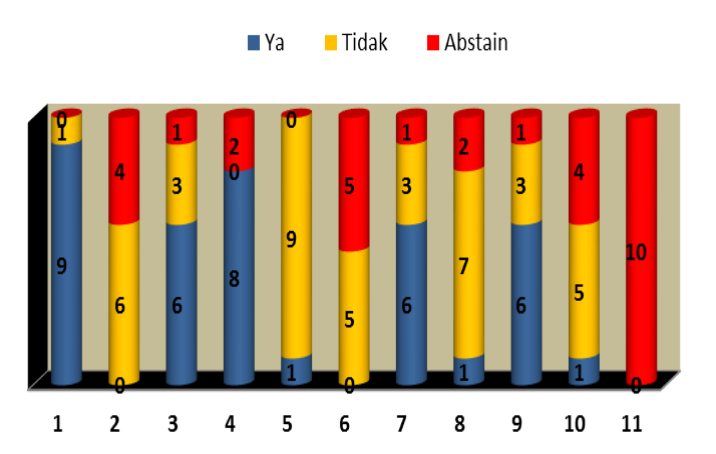

Gambar 6. Grafik Rekap Data Instrumen Assesmen AAC Level 4

Level 4 ada 11 anak menunjukkan bahwa subjek sudah mampu mendengarkan pembicaraan orang lain dan ada keinginan mengajukan pertanyaan, namun juga terbatas untuk cara menyampaikan. Hasil need asesmen ini dinyatakan oleh orang tua dan membuktikan orang tua memerlukan supaya putra-putrinya yang Cerebral Palsy mampu berkomunikasi. Kerterbatasan komunikasi dengan menggunakan bahasa verbal, mengharuskan AAC sebagai solusi untuk mengatasi kemampuan komunikasi anak Cerebral Palsy. Selanjutnya, juga diperkuat bahwa pada umumya orang tua menyatakan akan melatih putra-putrinya yang Cerebral Palsy mulai dari kode-kode yang terdapat di konteks kehidupan sehari-hari di keluarga, seperti keperluan makan, mandi, bermain dengan teman sebaya, dan tata cara yang dilakukan di lingkungan keluarga. Media yang dipilih adalah kartu gambar dan miniature benda asli. Media itu sebagai pengganti kode yang akan dikomunikasikan.

\section{Pembahasan}

Beberapa hasil temuan penelitian menunjukkan bahwa para orang tua menyatakan memerlukan latihan penggunaan AAC, sehingga dapat digunakan untuk melatih putra-putrinya yang Cerebral Palsy. Kebutuhan orang tua itu menunjukkan bahwa tang-gung jawab orang tua untuk mengoptimalkan putra putrinya yang Cerebral Palsy sebagai bagian dari tanggung jawab menjadi salah satu pusat dari pendidikan bagi generasi penerus bangsa, demikian konsep tri pusat pendidikan menurut Ki Hadjar Dewantoro, yang utama pada pusat di keluarga Haryanto (2011, pp. 19-20). Pem- bentuk pokok keluarga adalah orang tua, sehingga tanggung jawab pusat pendidikan yang utama dan terpenting pada orang tua.

Mampu berkomunikasi bagi putra putrinya yang Cerebral Palsy juga sebagian dari cita-cita luhur orang tua dan harapan kepada anaknya agar supaya dapat berperan serta dalam masyarakat. Sumarno (2011, pp. 8o-81) mengemukakan bahwa keluarga merupakan pendidikan informal yang berfungsi sebagai penyedia atau pengguna, tetapi tidak perjanjian kedua belah pihak. Maksudnya pendidikan dalam keluarga, pada orang tua mendidik anak-anaknya dengan sengaja berdasarkan cita-cita dan harapan kepada anak-anaknya. Pendidikan dalam keluarga yang dilakukan oleh orang tua merupakan konskuensi untuk membentuk keluarga dengan cita-cita yang luhur. Orang tua semuanya pasti bercita-cita dan harapan kepada keberadaan anak-anaknya sebagai generasi penerus yang mampu dewasa dan hidup dalam masyarakat. Mampu dewasa dan hidup di dalam masyarakat diperlukan suatu keterampilan komunikasi sebagai kebutuhan yang urgen.

Keterlibatan orang tua itu dimulai dengan proses need asesmen, karena yang akan menyediakan latihan dan kebutuhan kode-kode komunikasi yang paling mengetahui adalah orang tua. Kebutuhan kode-kode komunikasi digali dari orang tua, karena keberhasilan suatu komunikasi peserta didik juga tanggung jawab bersama orang-orang yang berkecimpung dalam pendidikan, namun konteks kehidupan sehari-hari lebih dihayati oleh orang tua. Penelitian yang mendukung disampaikan oleh Yuliati (2014, p.18) bahwa guru memiliki tanggung jawab untuk mengembangkan komunikasi peserta didik melalui mata pelajaran bahasa Indonesia, namun keberhasilan juga merupakan tanggung jawab semua pihak, yaitu guru, pemerintah, masyarakat, dan orang tua. Keberhasilan komunikasi bagi Cerebral Palsy amat krusial terletak pada orang tua, khususnya dalam mengembangkan komunikasi tambahan dan alternatif (Augmentative and Alternative Communication/AAC). AAC merupakan alternatif dari bentuk komunikasi yang tidak.menggunakan suara seperti halnya bicara atau sebagai pelengkap dari 
bicara (Hallahan \& Kauffman, 2003, p. 402). Kode atau koding dalam komunikasi dengan sistem AAC dapat digunakan gambar, benda asli yang dibuat sketsa, atau berupa photo yang mewakili sesuatu tentang pesan. AAC bagi Cerebral Palsy amat membantu dalam komunikasi, karena hambatan kognitif juga terbantu oleh penggunaan kode-kode yang konkrit dalam bentuk gambar atau simbol miniature dari benda, kegiatan, dan peristiwa. Demikian juga, AAC membantu Cerebral Palsy menyampaikan pesan komunikasi tanpa harus bersusah payah dengan berbicara,

Kode-kode yang konkrit dan berhubungan dengan konteks kehidupan seharihari membantu anak Cerebral Palsy memahami makna kode, karena pada umumnya anak Cerebral Palsy terjadi hambatan kognitif atau hambatan kecerdasan. Hambatan kecerdasan ini dikarenakan kelumpuhan pada otak berakibat pada fungsi fungsi untuk berpikir dan proses pengolahan informasi dari indera juga terhambat. Untuk itu, keterlibatan orang tua juga menentukan kode-kode AAC yang akan digunakan fungsional bagi anak, karena kode itu digunakan secara konteks dalam kehidupan keluarga. Demikian dikemukakan Light (1989, p. 138) "Functionality of communication implies utility withinthe demands of daily living. Functional skills are skills that are required within the natural environment: these skills must be performed by others when individuals are unable to fulfill the skill requirements themselves." Lingkungan keluarga yang dipandang alamiah dan lingkungan itu berfungsi sumber kode tetang kehidupan jika diusahakan oleh perang orang tua.

Hasil need asesmen juga menunjukkan bahwa di level 2 tentang keinginan anak untuk berkomunikasi, namun ketika di hasil kebutuhan untuk berinteraksi dan bekerja sama belum begitu tinggi kemampuannya memerlukan latihan rutin yang intensif. Latihan rutin intensif tersebut diperlukan, karena hambatan kognitif pada Cerebral Palsy memerlukan latihan dengan pendekatan behavioristik. Demikian itu merujuk pada penggunaan AAC sebagai komunikasi Cerebral Palsy perlu digunakan secara pembiasaan dalam lingkungan kehidupan anak Cerebral Palsy. Pembiasaan itu merujuk pada teori behavioristik yang dikembangkan B.F. Skinner, 1957 (Dunlap, 2009, p. 123) bahwa perkembangan bahasa diperlukan suatu latihan pembiasaan dengan penggunaan operant conditioning.

Pembiasaaan sebagai suatu latihan yang sesuai bagi Cerebral Palsy dalam menggunakan AAC juga merujuk pada (Millar et al., 2016, pp. 251-253) bahwa AAC memberi keuntungan perkembangan komunikasi, terutama bagi anak-anak yang hambatan perkembangan/developmental disabilities. Dengan demikian, AAC dengan penggunaan kode yang terkait kehidupan sehari-hari fungsional bagi anak-anak yang mengalami hambatan koginitif dan juga bagi anak yang tidak mampu komunikasi dengan suara verbal. Demikian juga, hasil yang menunjukkan orang tua lebih memilih penggunaan miniatur benda dan kartu gambar sebagai awal memudahkan orang tua mencari media AAC yang langsung dapat digunakan. Walaupun ini memerlukan intensitas orang tua untuk selalu melatih, karena keperluan dalam pembiasaan untuk penggunaaannya.

Rendahnya kemampuan anak yang berada di level 4 dan terlihat juga pada grafik menunjukkan bahwa subjek masih memerlukan latihan intensif, khususnya keterlibatan orang tua dalam pembiasaan dengan latihan. Latihan ini akan diperoleh secara alamiah, bahwa kode itu berfungsi juga untuk saling berinteraksi timbal balik. Kesulitan dalam memproduksi suara untuk bicara berakibat terhadap kompetensi komunikasi. Komunikasi dengan saluran suara dari bahasa verbal akan terhambat, karena kualitas suara yang digunakan untuk menyampaikan pesan sulit dimakna(decoding) atau diproses kodenya kembali(encoding) secara timbal balik. Kesulitan tersebut dibutuhkan juga untuk berlatih menggunakan kode secara timbal balik, sehingga peran orang tua dalam melatih pengembangan AAC bagi Cerebral Palsy amat kompleks.

\section{SIMPULAN}

Keterlibatan orang tua dalam mengembangkan komunikasi anak Cerebral Palsy dengan AAC amat krusial. Hal itu diperlukan karena keterbatasan kognitif 
pada anak Cerebral Palsy secara umum mengharuskan latihan dengan pembiasaan di lingkungan keluarga. Kode AAC yang dilatihkan akan fungsional jika itu kebutuhannya juga berdasarkan need asesmen dari orang tua. Demikian juga, kebutuhan penentuan bentuk kode yang terkait dengan konteks kehidupan sehari-hari di keluarga lebih fungsional ditentukan dan dikembangkan oleh orang tua. Dengan demikian, harapan orang tua akan memandirikan putra dan putrinya yang Cerebral Palsy dengan mampu komunikasi merupakan cita cita luhur terhadap keberadaan generasi penerus. Harapan itu diantaranya melatih anak Cerebral Palsy dengan AAC mulai level yang paling mudah menuju level yang dapat digunakan untuk berinteraksi. Kode dengan media miniatur benda asli dan kode pada kartu gambar lebih mudah dipilih orang tua pada saat awal akan mulai mengembangkan media AAC, karena itu yang paling mudah diadakan atau dibuat.

\section{DAFTAR PUSTAKA}

Dunlap, L. L. (2009). An introduction to early childhood special education: Birth to age five. Merrill/Pearson.

Hallahan, D. P., \& Kauffman, J. M. (2003). Exceptional learners: Introduction to special education (9th ed.). Boston: Pearson Education.

Hardman, M. L., Drew, C. J., \& Egan, M. W. (2002). Human exceptionality: Society, school, and family. Allyn and Bacon.

Haryanto. (2011). Pendidikan karakter menurut Ki Hadjar Dewantara. Yogyakarta. Retrieved from http://staff.uny.ac.id/sites/default/files/ 131656343/PENDIDIKAN KARAKTER MENURUT KI HAJAR

\section{DEWANTORO.pdf}

Kauffman, J. M., \& Hallahan, D. P. (2011). Handbook of special education. Routledge.

Light, J. (1989). Toward a definition of communicative competence for individuals using augmentative and alternative communication systems. Augmentative and Alternative Communication, 5(2), 137-144. http://doi.org/10.108o/0743461891233127 5126

Millar, D. C., Light, J. C., \& Schlosser, R. W. (2016). The Impact of Augmentative and Alternative Communication Intervention on the Speech Production of Individuals With Developmental Disabilities: A Research Review. Journal of Speech Language and Hearing Research, 49(2), 248. http://doi.org/10.1044/10924388(2006/021)

Reynolds, C. R., \& Fletcher-Janzen, E. (2008). Encyclopedia of Special Education. (C. R. Reynolds \& E. Fletcher-Janzen, Eds.). Hoboken, NJ, USA: John Wiley \& Sons, Inc.

http://doi.org/10.1002/9780470373699

Sumarno. (2011). Peran pendidikan nonformal dan informal dalam pendidikan karakter bangsa. Cakrawala Pendidikan, XXX(Edisi Khusus Dies Natalis UNY), 73-84. Retrieved from https://lppmp.uny.ac.id/sites/lppmp.un y.ac.id/files/o7 Sumarno.pdf

Yuliyati. (2014). Model budaya baca-tulis berbasis balance literacy dan gerakan informasi literasi di SD. Jurnal Ilmu Pendidikan, 20(1). http://doi.org/10.17977/JIP.V2oI1.4386 